\title{
The Concept of Care in Nursing
}

\section{Maria Lavdaniti*}

Nursing Department Technological Educational Institute of Thessaloniki-Greece

"Corresponding author: Maria Lavdaniti, Assistant professor, Nursing Department Technological Educational Institute of Thessaloniki-Greece, Tel: +0306937865660; E-mail: maria_lavdaniti@yahoo.gr

Received date: December 16, 2014, Accepted date: December 19, 2014, Published date: December 22, 2014

Copyright: @ 2014 Lavdaniti M. This is an open-access article distributed under the terms of the Creative Commons Attribution License, which permits unrestricted use, distribution, and reproduction in any medium, provided the original author and source are credited.

\section{Editorial}

\section{The concept of care in Nursing}

The concept of nursing has many definitions. It is understood and viewed differently by the nurses themselves, by nursing students and other health professionals. This diversity can be explained by different educational backgrounds, cultures and experiences [1]. In the past, there were many definitions for nursing, including the definitions drawn up by national nurses' associations and the definitions in the major nursing theories and models (e.g. Johnson, King, Levine, Orem, Watson, Leininger etc) [2]. Recently, the International Council of Nursing introduced a new and improved definition of nursing: "Nursing encompasses autonomous and collaborative care of individuals of all ages, families, groups and communities, sick or well and in all settings. Nursing includes the promotion of health, prevention of illness and the care of ill, disabled and dying people. Advocacy, promotion of a safe environment, research, participation in shaping health policy and in patient and health systems management, and education, are also key nursing roles." [3]

As can be seen in the existing definitions, care is the core concept of nursing [1] and it is fundamental in nursing practice [4]. The concept of care emerged during the decade of the 1950's, but many factors hampered its development. It was not until two decades later that not only the first National Caring Research Conference but also the publication of Watson's theory stimulated the interest of researchers in the concept [4].

According to the free dictionary definition caring is a "feeling and exhibiting concern and empathy for others showing or having compassion". Care is a concept occurring frequently in nursing literature [2], to the point that it is even characterized as ubiquitous. Although phenomenon of care is universal, there is no universally accepted definition thereof. It is maintained that "caring has been formalized through nursing theories and specifically through Watson's theory" [5]. In Watson's theory "there are three major elements or carative factors, the transpersonal caring relationship and the caring occasion/caring moment" [6]. Within her nursing theory, caring consists of "carative factors that result in the satisfaction of human needs"[2]. In 1981, Leininger wrote that in order to define caring it is necessary to describe the individual activities meant to provide support and assistance or aimed at helping patients to help themselves. According to Watson the concept of caring encompasses that of nursing as well, in that from an ethical perspective, caring is the ideal form of nursing, since its goal is the promotion of patients' dignity [7].

In recent nursing literature there are accounts of the concept of care/ caring, which has been described by nurses, nursing students and nursing instructors. Dyson has maintained that the five most reported characteristics of caring in the literature include care as human trait, as a moral imperative, as an effect, as an interpersonal interaction and as a therapeutic intervention [2]. Coyle-Rogers has told of the lived experience of caring, which consists of intuitive discovery, supportive guidance, respect, promoting independence, risk rating and shared success. Brilowski \& Wendler in their evolutionary concept analysis, conclude that the core attributes of the concept of care are: relationship, action, attitude, acceptance and variability [4]. Also, it is reported that "the fundamental aspect of nursing is caring and the ethos of caring is love". Love cannot be taught but it can be expressed or experienced and sometimes lack of love means lack of care [8]. The concept of care is referred to by students as well. In a recent study, care is described as "an emotional offer", "a service", "activities provided to an individual or a group", "physical and psychological support" and as "a constant phenomenon"[9].

According to the author's opinion, care includes love shown to patients, the respect of human rights and dignity, support and honesty towards patients and their families and sound cooperation with other health professionals. In addition, it has to be based on recent evidence and must be provided by skilled nurses in order to ensure safe and high quality nursing care. As nursing instructors, we are obliged to teach our students the art and the science of nursing care and inspire in them the concept of care. We must remember at all times that care is the essence of and the motivation for nursing and that it is one of the leading factors capable of empowering the nursing profession.

\section{References}

1. Sapountzi-Krepia D (2013) Some Thoughts on Nursing. Int J Caring Sci 6:127-133

2. Dalpezzo NK (2009) Nursing care: a concept analysis. Nurs Forum 44:256-64.

3. Definition of nursing. International Council of Nursing 2014.

4. Brilowski GA, Wendler MC (2005) An evolutionary concept analysis of caring. J Adv Nurs 50:641-50.

5. Huynh T, Alderson M, Thompson M (2008) Emotional labour underlying caring: an evolutionary concept analysis. J Adv Nurs 64:195-208.

6. Lachman VD (2012) Applying the ethics of care to your nursing practice. Medsurg Nurs 21:112-4, 116.

7. Coyle-Rogers P (2004) Shared success: the challenge of caring for today's health occupations educators. J Car Techn Educ 20: 9-26

8. Emakpor C, Nyback MH (2010) Love: A relevant concept in Nursing and caring science. Vaasa Novia University of Applied Sciences.

9. Sapountzi-Krepia D, Lavdaniti M, Psychogiou M, Tsiligiri M, Karassavidis S, et al. (2013) The Concept of "Care" as Perceived by Greek Nursing Students: a Focus Group Approach. Int J Caring Sci 6: 392-401. 